as local secretaries, and were responsible with him for the admirable arrangments throughout the Congress.

The annual dinner was held at the Central Station Hotel, Glasgow, on May 1. There were 69 present, the arrangements were admirable, and reflected great credit on the local secretaries.

\title{
ANNOTATIONS
}

\section{Alternating Current Lighting and Eyestrain}

We would draw the attention of readers to a letter from $\mathrm{Mr}$. J. C. Elvy, Consulting Engineer, addressed to the Editor of the Lancet, which appears in the issue for April 26 last. Mr. Elvy thinks that there may be some connection between alternating current lighting and eyestrain. Personally, he finds himself more comfortable when working in his office with direct current lighting than when reading at home with alternating current lighting. He also says: "It would be interesting to hear the experience of surgeons when conducting delicate operations under these two different conditions-alternating versus direct-as with alternating it is possible to detect several images of bright metallic instruments especially when these are in motion, similar to "cinematograph" action. The "cinematograph" effect is most pronounced in the low wattage "Neon" nightlight bulbs when used on an alternating current circuit. Perhaps ophthalmic surgeons could throw some light on the apparent increase in the use of spectacles in certain areas." The Editor remarks that it is undoubtedly the case that with a cycle of alternation of less than 25 there is a perceptible flicker which is trying to the eyes. He also remarks that while, as he understands, there are 25-cycle plants which supply lighting as well as power, there is no supply of alternating current at less than 50 alternations for lighting. Even at this speed there may be a slight cyclic variation in the light, especially from the low-power high-voltage metal filament incandescent lamp, in which the mass of the filament, and, therefore, the stored heat energy is very low. The Editor of the Lancet recommends the point as one which ophthalmic surgeons might consider.

It may be of interest to record an instance in which a factory was lighted by alternating current. In one of the sheds there were several circular saws and the management had deemed it necessary to transform the current supplying this shed to a constant current in order to avoid risk of injury; because if the rate of rotation of the saws was such that the movement of the teeth was in phase with the alternation of the current, the saw would appear to be stationary. 